\title{
Extracellular Space Diffusion and Extrasynaptic Transmission
}

\author{
L. VARGOVÁ, E. SYKOVÁ \\ Department of Neuroscience, Charles University, Second Medical Faculty and Department of \\ Neuroscience, Institute of Experimental Medicine, Academy of Sciences of the Czech Republic, \\ Prague, Czech Republic
}

Received February 15, 2008

Accepted April 16, 2008

On-line May 13, 2008

\section{Summary}

The diffusion of neuroactive substances in the extracellular space (ECS) plays an important role in short- and long-distance communication between nerve cells and is the underlying mechanism of extrasynaptic (volume) transmission. The diffusion properties of the ECS are described by three parameters: 1. ECS volume fraction $\alpha$ ( $\alpha=$ ECS volume/ total tissue volume), 2 . tortuosity $\lambda$ ( $\lambda^{2}=$ free /apparent diffusion coefficient), reflecting the presence of diffusion barriers represented by, e.g., fine neuronal and glial processes or extracellular matrix molecules and 3. nonspecific uptake $k^{\prime}$. These diffusion parameters differ in various brain regions, and diffusion in the CNS is therefore inhomogeneous. Moreover, diffusion barriers may channel the migration of molecules in the ECS, so that diffusion is facilitated in a certain direction, i.e. diffusion in certain brain regions is anisotropic. Changes in the diffusion parameters have been found in many physiological and pathological states in which cell swelling, glial remodeling and extracellular matrix changes are key factors influencing diffusion. Changes in ECS volume, tortuosity and anisotropy significantly affect the accumulation and diffusion of neuroactive substances in the CNS and thus extrasynaptic transmission, neuron-glia communication, transmitter "spillover" and synaptic cross-talk as well as cell migration, drug delivery and treatment.

\section{Key words \\ Diffusion - Extracellular volume - Tortuosity - Magnetic resonance}

\section{Corresponding author}

E. Syková, Institute of Experimental Medicine AS CR, Vídeňská 1083, 14220 Prague 4, Czech Republic. Fax: + 420241062782.

E-mail: sykova@biomed.cas.cz

\section{Introduction}

The correct transfer of neuroactive substances and ions between nerve cells is fundamental for signal transmission in the central nervous system (CNS). Besides the classical synaptic transmission resulting from the activation of receptors located on the postsynaptic membrane, extrasynaptic transmission, based on the diffusion of neuroactive substances through the volume of the extracellular space (ECS), represents an alternative and less specific mode of signal transfer, which may in turn modulate signal transmission via synapses.

Strictly speaking, synaptic transmission itself requires the diffusion of neuroactive substances over short distances (across the synaptic cleft and in the close vicinity of the synapse), which allows communication between preand postsynaptic terminals and the astrocytic processes enwrapping the synapse (Fig. 1A). Due to transport mechanisms on astrocytic processes, astrocytes may suppress or facilitate neuronal activity by neurotransmitter uptake or release (for review see Haydon 2001). The importance of glial cells for synaptic transmission was reflected in the model of a ,tripartite synapse“ (Araque $e t$ al. 1999). The recent model of a "quadripartite synapse“ adds a fourth important element - the extracellular space with its dynamically changing content and its diffusion properties (Syková 2004a, Fig. 1A).

The existence of extrasynaptic communication between cells over longer distances, several tens or hundreds of micrometers (Fig. 1B), was hypothesized in the second half of the $20^{\text {th }}$ century because of frequent functional interactions between nerve cells without any 
morphological (synaptic) contacts, "mismatches" between release sites and the locations of receptors and the existence of abundant high-affinity extrasynaptic receptors (Herkenham 1987). Early studies by Vizi (1974) showed an indirect influence between sympathetic and parasympathetic activity without any obvious synaptic contact. Later, it was found that extrasynaptic communication is a general feature of the central nervous system, contributing to the synchronizing of neuronal activity in many complex functions such as sleep and vigilance, lactation, chronic pain, depression, memory formation and other plastic functions of the brain (for review see (Syková 2004a,b, Vizi et al. 2004). The phenomena was named extrasynaptic or volume transmission (Fuxe and Agnati 1991), since its underlying mechanism is the diffusion of neuroactive substances through the volume of the ECS, which therefore serves not only as the microenvironment of nerve cells but also as a communication channel. Volume transmission has been intensively studied during the last few decades, however, its importance in modulating and mediating various functions is still not completely recognized (Syková 1997, 2004a,b, Vizi et al. 2004).

Volume transmission is also necessary for an important phenomena called "synaptic cross-talk" (Kullmann et al. 1996, Asztely et al. 1997). This heterosynaptic communication, whereby synapses of independent pathways may influence each other and modulate one another's activity, plays a role, for example, during long-term potentiation (LTP) and depression (LTD), during lactation or dehydration, where it can potentiate hormonal release (Oliet et al. 2001, Piet et al. 2004), or in the indirect modulation of the dopaminergic system by excitatory input (Kiss et al. 2004). This synaptic cross-talk requires the escape of neurotransmitters from the synaptic cleft (called synaptic spillover), prevented in so-called "private" synapses by the ensheathing of these synapses by glial processes and the extracellular matrix (ECM), which contributes to the high selectivity and signal-to-noise ratio of synaptic transmission (Fig. 1A). During certain conditions, e.g. lactation (Theodosis and Poulain 1993), or in "open" synapses, this insulation is missing and synaptic spillover occurs especially during repetitive stimulation. Via diffusion, neurotransmitters such as glutamate or GABA can thus reach extrasynaptic receptors in a neighboring synapse.

Besides synaptic spillover, neuroactive substances and ions may be released into the ECS by various mechanisms, including extrasynaptic vesicular release from neurons or axonal varicosities (neuropeptides or catecholamines), the reversal action of glial transporters for transmitters (glutamate, GABA, dopamine), ionic shifts from the intracellular to the extracellular compartment or by the release of gaseous transmitters such as nitric oxide (Zoli et al. 1999). The diffusion of neurotransmitters in the ECS and the accumulation of ions in the ECS are important for neuron-glia communication. While neurons can interact by both synaptic and extrasynaptic (volume) transmission, communication between neurons and glial cells is limited to the extrasynaptic type. Information about ongoing neuronal activity and the current state of the neurons is crucial for the glial cells' maintenance of ionic, $\mathrm{pH}$ and volume homeostasis and their modulation of synaptic transmission efficacy.

\section{Extracellular space and its diffusion parameters}

Diffusion is characterized by the random Brownian motion of molecules and in a free medium is described by Fick's laws. According to Kuffler and Potter (1964), brain tissue resembles a foam, in which the cells correspond to the gaseous phase and the ECS represents the water phase. For substances that do not cross the cell membranes, the brain acts as a porous medium, in which diffusion in the ECS is restricted by its geometry and composition. To describe diffusion in the ECS, we must take into account the size of the extracellular pores, the diffusion barriers represented by neuronal and glial processes and ECM molecules and cellular uptake. Therefore, Nicholson and Phillips (1981) modified Fick's original diffusion equations by introducing three diffusion parameters: extracellular volume fraction $(\alpha)$, tortuosity $(\lambda)$ and non-specific concentration dependent or independent uptake ( $\left.\mathrm{k}^{\prime}\right)$ (Fig 1B). ECS volume fraction $\alpha$ is a dimensionless quantity defined as the ratio between the volume of the ECS and the total tissue volume. Early studies with electron microscopy determined the volume of the ECS to be as low as $5 \%$ of total tissue volume with cells spaced 10-20 nm apart on average (van Harreveld et al. 1971). However, animal death almost certainly causes ischemia and cell swelling concomitant with ECS shrinkage, and the classical methods used for the fixation and embedding of the tissue cause dehydration, thus leading to a diminished ECS volume. Now it is evident that the ECS represents about 20-25\% 

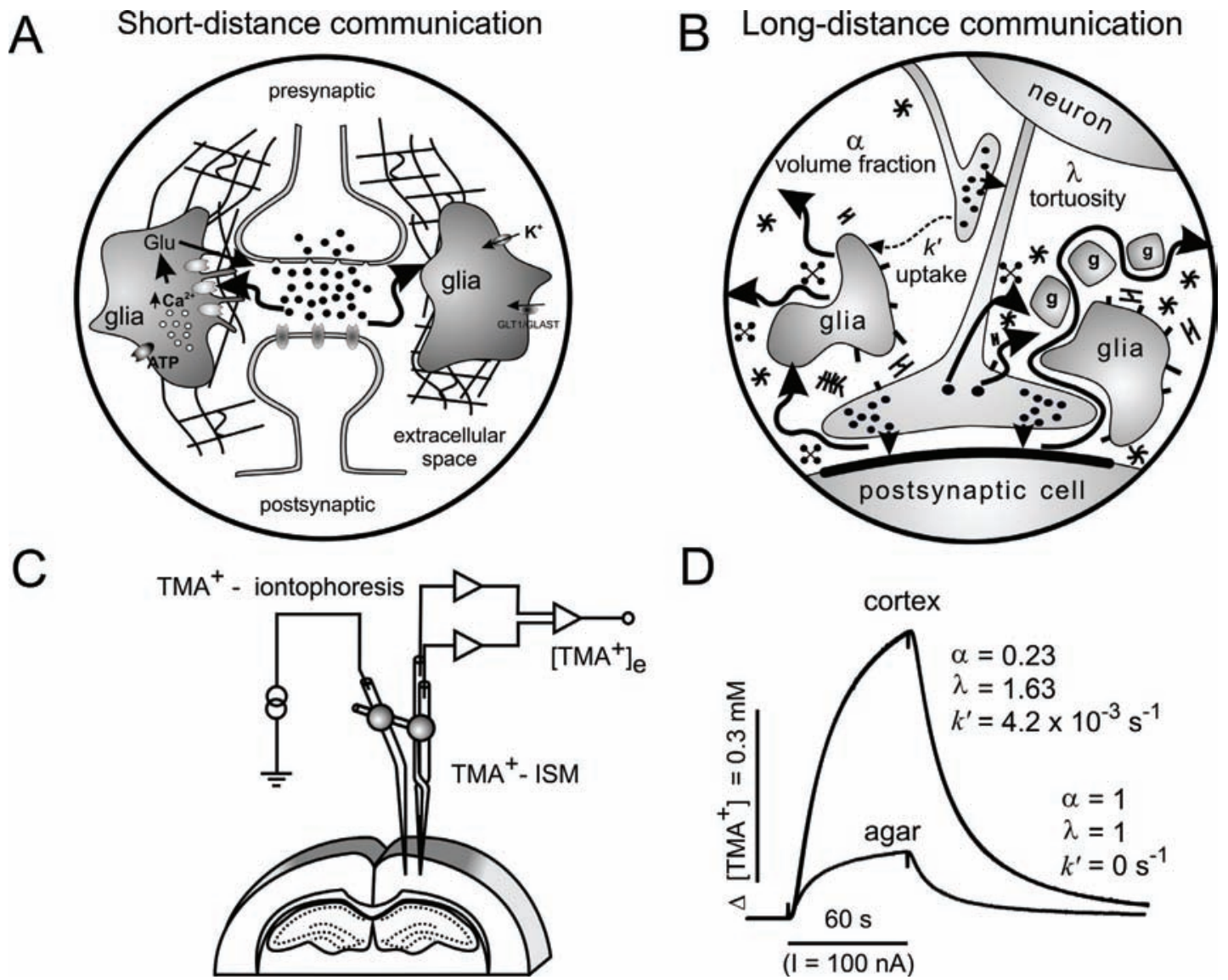

Fig. 1. A: Scheme of short-distance communication between cells and a quadripartite synapse, in which signal transmission is affected by four important elements: presynaptic and postsynaptic terminals, glial processes closely ensheathing the synapse and the extracellular space (ECS) with its content, particularly the extracellular matrix. B: Long-distance communication between nerve cells via diffusion is critically dependent on three ECS diffusion parameters: volume fraction $\alpha$, tortuosity $\lambda$ and non-specific uptake $k^{\prime}$. C: Scheme of the experimental arrangement for measuring the ECS diffusion parameters by the tetramethylammonium (TMA $\left.{ }^{+}\right)$realtime iontophoretic method. TMA ${ }^{+}$is iontophoretically released into the tissue; changes in its concentration over time are followed by an ion-selective microelectrode (ISM), glued to an iontophoretic micropipette at a known distance. D: Representative diffusion curves recorded during an iontophoretic pulse in agar and in the brain cortex with the corresponding values of $\alpha, \lambda$ and $k^{\prime}$ obtained by curve fitting. Diffusion in diluted agar is free and by definition, $\alpha=1=\lambda$ and $k^{\prime}=0$. The higher amplitude and the different shape of the curve recorded in the brain reflect the fact that diffusion in the tissue is restricted by the pore size between the cells and hindered by diffusion barriers.

of the adult healthy brain tissue, so $\alpha=0.20-0.25$. ECS tortuosity $\lambda$ is defined as the square root of $\mathrm{D} / \mathrm{ADC}$, where $\mathrm{D}$ is the free diffusion coefficient and $\mathrm{ADC}$ is the apparent diffusion coefficient of a substance in the nervous tissue. The tortuosity value reflects the number and extent of diffusion barriers and in healthy tissue is about 1.5 , which means that diffusion in the brain is about $2.5 \mathrm{x}$ slower than in a free medium. Tortuosity is a tensor and in anisotropic regions has different values in different directions. Besides non-specific, concentration dependent uptake $\left(\mathrm{k}^{\prime}\right)$, in many cases substances such as glutamate are transported by energy-dependent uptake systems that obey non-linear kinetics.

Currently, the best method for measuring the absolute values of the ECS diffusion parameters is the real-time iontophoretic method, developed by Nicholson and Phillips (Nicholson and Phillips 1981) (Fig. 1C). This method allows us to determine the absolute values of all three diffusion parameters and their dynamic changes in nervous tissue in vitro as well as in vivo. The method is based on the iontophoretic application of ions to which cell membranes are relatively impermeable (tetramethylor tetraethylammonium $-\mathrm{TMA}^{+}$or $\mathrm{TEA}^{+}$) into the ECS. The concentration of the ions is determined by an ionselective microelectrode fixed at a known distance (100-200 $\mu \mathrm{m})$ from the iontophoretic micropipette. The resulting diffusion curve (Fig. 1D) is mathematically analyzed, and the values of $\alpha, \mathrm{ADC}_{\mathrm{TMA}}, \lambda$ and $\mathrm{k}^{\prime}$ are extracted by a non-linear curve-fitting simplex algorithm operating on the diffusion curve.

The other methods used to study ECS volume fraction and tortuosity are less comprehensive (Nicholson and Syková 1998, Syková 2004b). These methods can either measure only one of the parameters, follow only 
relative changes in the ECS volume fraction, or detect changes that are only partially related to ECS volume changes. The methods include the measurement of tissue resistance, changes in light transmittance and/or scattering, the measurement of the ADCs of fluorescentlabeled large molecules, polymers and quantum dots by integrative optical imaging, and the measurement of the ADC of water $\left(\mathrm{ADC}_{\mathrm{W}}\right)$ by diffusion-weighted MRI (DWMRI). DW-MRI reveals the inhomogeneous and anisotropic diffusion of water, similar to the diffusion of $\mathrm{TMA}^{+}$(Vořrišek et al. 2002). In comparative studies in which measurements were first done using DW-MRI and then in the same animal or experimental model using the real-time iontophoretic method, we have found that under some experimental conditions, a decrease in $\mathrm{ADC}_{\mathrm{W}}$, i.e. lower diffusibility, can be related either to a decrease in $\alpha$, typically during fast acute changes such as ischemia (van der Toorn et al. 1996), or to an increase in the number of diffusion barriers, represented as an increase in $\lambda$, without substantial changes in $\alpha$, such as occur during chronic states post-injury (Voříšek et al. 2002).

\section{Heterogeneity and anisotropy in the ECS}

The ECS is heterogeneous, which means that its properties differ over microscopic, e.g. around different types of cells, as well as over macroscopic scales, in different brain regions. An analysis of glial cell tail currents showed that the ECS volume in the vicinity of oligodendrocytes is smaller than that around astrocytes (Vargová et al. 2001a, Chvátal et al. 2004). Moreover, the structure of cell aggregates, the organization of myelin sheaths, glial processes and the ECM may create a preferential channel for the diffusion of molecules in a certain direction, such as along myelinated axons (Prokopová et al. 1997, Vořriššk and Syková 1997a), so that diffusion is anisotropic. In anisotropic regions, nonsynaptic transmission gains a certain degree of specificity. Anisotropy has been found also in grey matter - in the molecular layer of the cerebellum (Rice et al. 1993), in the grey matter of the hippocampus (Mazel et al. 1998) and in the hypothalamic supraoptic nucleus (SON) (Piet et al. 2004). The appearance and disappearance of diffusion anisotropy reflects persistent or plastic tissue remodeling, for example myelination during development, the loss of the typical organization of astrocytic processes in the hippocampus during aging or structural changes of astrocytes in the SON during lactation or dehydration.

\section{ECS diffusion parameters and glial cells}

Glial cells play an important role in different brain functions. Voltage- and ligand-activated channels and a number of transport mechanisms on the glial membrane allow neuron-glia communication and the maintenance of ionic and volume homeostasis, which is crucial for proper neuronal function. The activation of glial cells leads to the activation of ion channels, second messengers and intercellular metabolic pathways and subsequently to changes in glial volume, accompanied by dynamic variations in $\alpha$, structural changes of astrocytic processes and, eventually, the production of extracellular matrix. Astrocyte swelling is an early event in numerous pathological states, accompanied by an elevation of $\left[\mathrm{K}^{+}\right]_{\mathrm{e}}$, a decrease of extracellular osmolality and increased concentrations of excitatory amino acids. Under experimental conditions, all of these manipulations evoked a decrease in extracellular volume and an increase in tortuosity, which corresponded histologically with a significant increase in glial fibrillary acidic protein (GFAP) staining and changes in astrocytic morphology, typical of astrogliosis (Syková et al. 1999, Vargová et al. 2001b). Even if further study did not confirm a true astrogliosis, since the total GFAP content was not increased (Neprašová et al. 2007), substantial changes in astrocyte morphology and the rearrangement of astrocytic processes have been found in hypotonic medium using 3D reconstruction of confocal images (Chvátal et al. 2007).

Reactive gliosis, including hypertrophy, hyperplasia and morphological remodeling of astrocytes and nerve cell loss are typical features of damaged tissue. Qualitative and quantitative changes were detected in the production of extracellular matrix (ECM) molecules in active astrocytes. Changes in the ECS diffusion parameters related to glial maturation, swelling and/or remodeling have been studied under physiological and pathological conditions (for review see (Syková 2004b, 2005) - a few of which are described below in more detail.

\section{ECS diffusion parameter changes during physiological states}

The ECS diffusion parameters are not stable but in fact change significantly even in physiological states such as development, aging, neuronal activity or during specific physiological conditions, e.g. lactation. The 

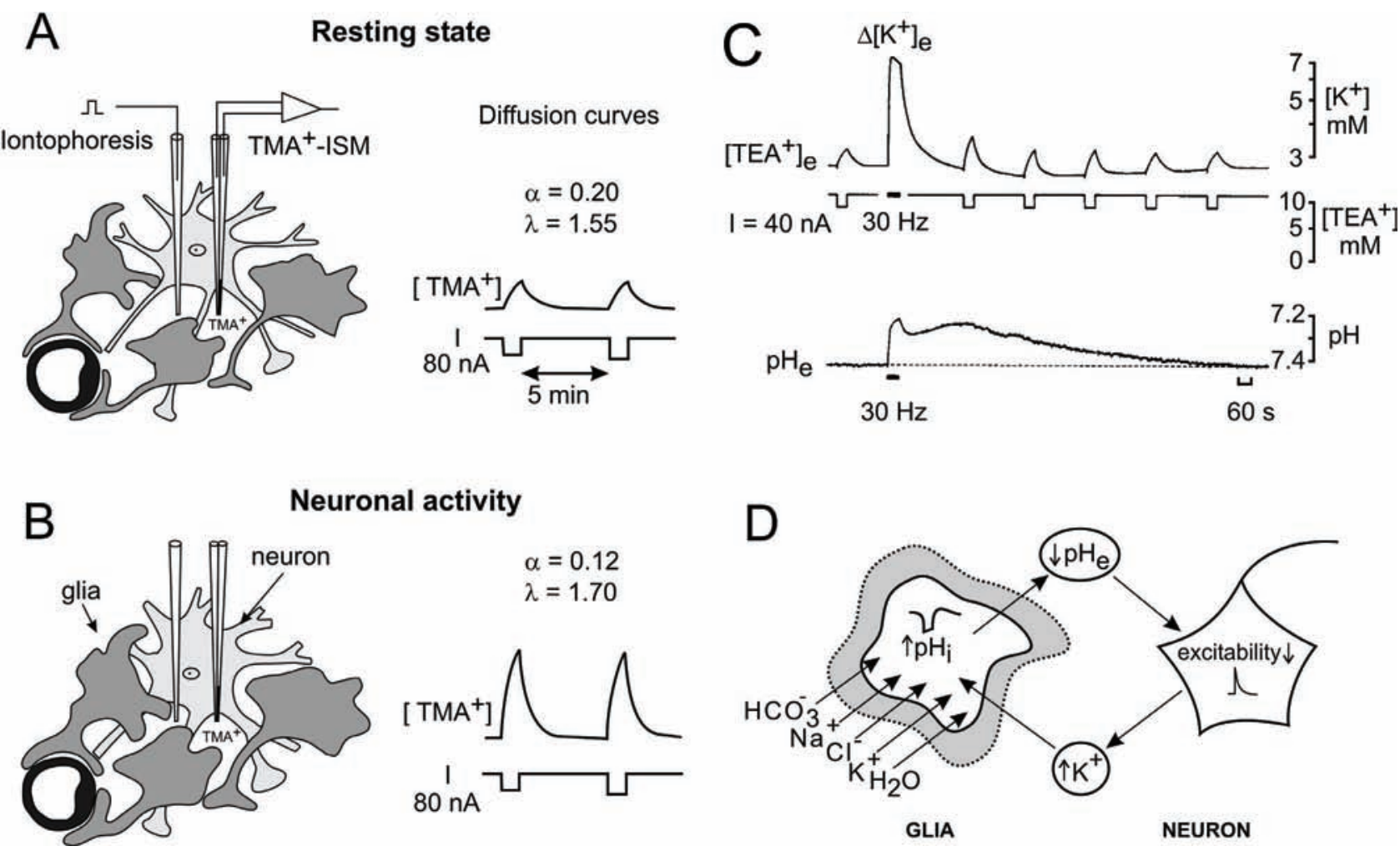

Fig. 2. A, B: Experimental set-up and examples of diffusion curves, along with the corresponding values of the ECS diffusion parameters, recorded in the rat brain during a resting state and during physiological neuronal activity. C: Effect of repetitive stimulation (30 Hz/min) of the dorsal roots on TEA diffusion curves, extracellular $\mathrm{K}^{+}\left(\left[\mathrm{K}^{+}\right]_{\mathrm{e}}\right)$ and $\mathrm{pH}\left(\mathrm{pH}_{\mathrm{e}}\right)$ in the dorsal horns of the isolated frog spinal cord. Stimulation evoked an increase in $\left[\mathrm{K}^{+}\right]_{\mathrm{e}}$ and an acid shift in the extracellular space. The time course of the acid shift correlates with a decrease in the ECS volume, manifested as an increase in the amplitude of the diffusion curves; these changes outlasted the stimulation for $30 \mathrm{~min}$. D: Model of a nonspecific feedback mechanism suppressing neuronal activity due to the acidification of the extracellular space and glial swelling. For a detailed description, see text. From Syková (2003).

volume fraction decreases throughout the entire postnatal life in rats, with the steepest fall in the first three weeks (Lehmenkuhler et al. 1993, Prokopová et al. 1997, Vořrišek and Syková 1997a); a remarkable difference was also found between adult and aged tissue (Syková et al. 1998). This long-term decrease in volume fraction can be attributed to changes in ECM composition, neuronal migration, the development of dendritic arborization, rapid myelination and the proliferation of glia. The connection between gliogenesis and ECS diffusion parameters is probably most evident in the white matter, where the period of the gradual myelination of the corpus callosum closely corresponds with a decrease in extracellular volume fraction and the appearance of anisotropy (Voříšek and Syková 1997a). The almost doubled volume fraction (0.35-0.40) observed in immature tissue is a protective factor that slows down any increase in the concentration of neuroactive substances to neurotoxic levels during pathological states such as ischemia (Voříšek and Syková 1997b) or epilepsy (Kilb et al. 2006).

Ions crossing the cell membrane during neuronal activity are in a hydrated state and therefore their movement is accompanied by water molecules, which leads to cell swelling and compensatory ECS shrinkage (Fig. 2A, B). Repetitive electrical stimulation of the dorsal root of the rat or frog spinal cord causes a substantial increase in $\left[\mathrm{K}^{+}\right]_{\mathrm{e}}$ and a decrease in $\alpha$ from about 0.24 to $0.17-0.12$, i.e. of $30-50 \%$ (Svoboda and Syková 1991). The changes in ECS diffusion parameters, however, persist after stimulation ends (30 min after one minute of electrical stimulation or even $120 \mathrm{~min}$ after 3 min of stimulation, Fig. 2C). A connection between ionic and volume changes has been proposed in a model of a nonspecific feedback mechanism suppressing neuronal activity (Fig. 2D). In this model, depolarization of astrocytic membranes due to an activity-related increase in extracellular potassium ions $\left(\left[\mathrm{K}^{+}\right]_{\mathrm{e}}\right)$ activates transport mechanisms, resulting in the acidification of the ECS which in turn suppresses neuronal firing since an acid shift can change the conformation of receptor proteins (Syková 1997). The increase in $\left[\mathrm{K}^{+}\right]_{\mathrm{e}}$ activates glial homeostatic mechanisms for extracellular potassium, which leads to glial uptake of $\mathrm{K}^{+}$from the 
ECS and specific $\mathrm{Na}^{+}-\mathrm{HCO}_{3}{ }^{-}$cotransport, leading to an intracellular alkaline shift in glia and a compensatory extracellular acid shift. Acidification, glial swelling and compensatory ECS shrinkage result in a further increase in $\left[\mathrm{K}^{+}\right]_{\mathrm{e}}$ in the ECS until the neuronal activity eventually stops.

More persistent, however, but still recoverable changes in the diffusion parameters are evoked by the rebuilding of glial cell structure in the hypothalamic SON during lactation or dehydration. In rat males and virgin females, the SON is an anisotropic structure with a relatively large extracellular volume $(\alpha=0.32)$ and preferential diffusion along the ventrodorsal axis (Piet et al. 2004). This anisotropy is in agreement with the orientation of the majority of astrocytic processes, which separate magnocellular neurons and their dendrites and prevent them from direct contact. During lactation, glial processes are retracted towards the basal lamina, which leads to a significant reduction in the astrocytic coverage of the magnocellular neurons (Theodosis and Poulain 1993), the disappearance of anisotropy and facilitated diffusion (Piet et al. 2004). A relative absence of glial processes around glutamatergic synapses results in the insufficient clearance of glutamate and thus increases its level in the ECS (Oliet et al. 2001). Glutamate spillover and cross-talk between glutamate and GABA-ergic pathways are greatly enhanced due to the facilitated diffusion, as was confirmed by the increased depression of GABA-ergic transmission mediated by metabotropic glutamate receptors (Piet et al. 2004). Modulation of the strength of excitatory and inhibitory pathways by heterosynaptic cross-talk may represent one of the mechanisms regulating oxytocin production, milk ejection and water homeostasis in the rat supraoptic nucleus.

\section{ECS diffusion parameter changes during pathological states}

Almost all CNS pathologies are connected with pronounced changes in the ECS diffusion properties with obvious consequences for extrasynaptic transmission. The way in which the ECS volume fraction and tortuosity change depends not only on the character of the evoking stimulus, but also on how rapidly these changes occur (Fig. 3). Acute states such as ischemia/anoxia are accompanied by dramatic cell swelling leading to ECS shrinkage of about $60-75 \%$, to as little as $\alpha=0.05$ (van der Toorn et al. 1996, Voříšek and Syková 1997b,
Homola et al. 2006). Tortuosity is increased above 2.0 concomitantly with the reduction of $\alpha$, since the concentration of the existing diffusion barriers is higher in the smaller space (Fig. 3A). Interestingly, the same ultimate changes have been found in neonatal, adult and aged rats, in grey as well as in white matter and in different brain regions (cortex, corpus callosum and spinal cord). However, the initial values of $\alpha$ are higher and the time course of ischemia/anoxia-evoked changes slower in immature tissue and white matter, which corresponds with their well-known greater resistance to anoxia/ischemia in comparison with adult or even aged tissue.

If the onset of a pathological state is less rapid or in its chronic phase, the extracellular volume fraction and tortuosity may change independently from each other. For example, in a pilocarpine-induced status epilepticus (SE) model, only a decrease in the ECS volume of about $30 \%$ was detected with no significant changes in tortuosity (Slais et al. 2007). The decrease in $\alpha$ began concurrently with an increase in $\left[\mathrm{K}^{+}\right]_{\mathrm{e}}$ within the first minutes after pilocarpine injection. The onset of the first ictal discharges came 30 minutes later, and the maximum discharge amplitudes were reached in 40-50 min after pilocarpine injection, corresponding to a maximum decrease in $\alpha$ of about $30 \%$ from its initial value. This correlation suggests the possible contribution of an ECS volume reduction to the initiation of $\mathrm{SE}$ and shows the effect of changes in ECS volume on neuronal activity. Indeed, in the immature hippocampus, the large extracellular space represents a protective mechanism counteracting the greater susceptibility of immature tissue to excitatory stimuli. Hypoosmolar conditions, which lead to a reduction in ECS volume in immature tissue to similar values as seen in adults, also result in increased frequency of epileptiform discharges, while hyperosmolar conditions reduce neuronal excitability (Kilb et al. 2006).

Typically, ECS volume and tortuosity behave independently in chronic pathological states, especially in those accompanied by tissue damage and subsequent astrogliosis (Fig. 3B). The value of $\alpha$ reflects the actual situation resulting from cell death and astrocytic hyperplasia, while tortuosity is increased in almost all cases due to additional diffusion barriers formed by astrocytic hyperplasia, hypertrophy, the rebuilding of fine processes and the production of extracellular matrix. A stab wound of the rodent brain is a well-characterized and commonly used model of reactive gliosis (Norton et al. 1992). In the close vicinity (300-1000 $\mu \mathrm{m})$ of the wound, 

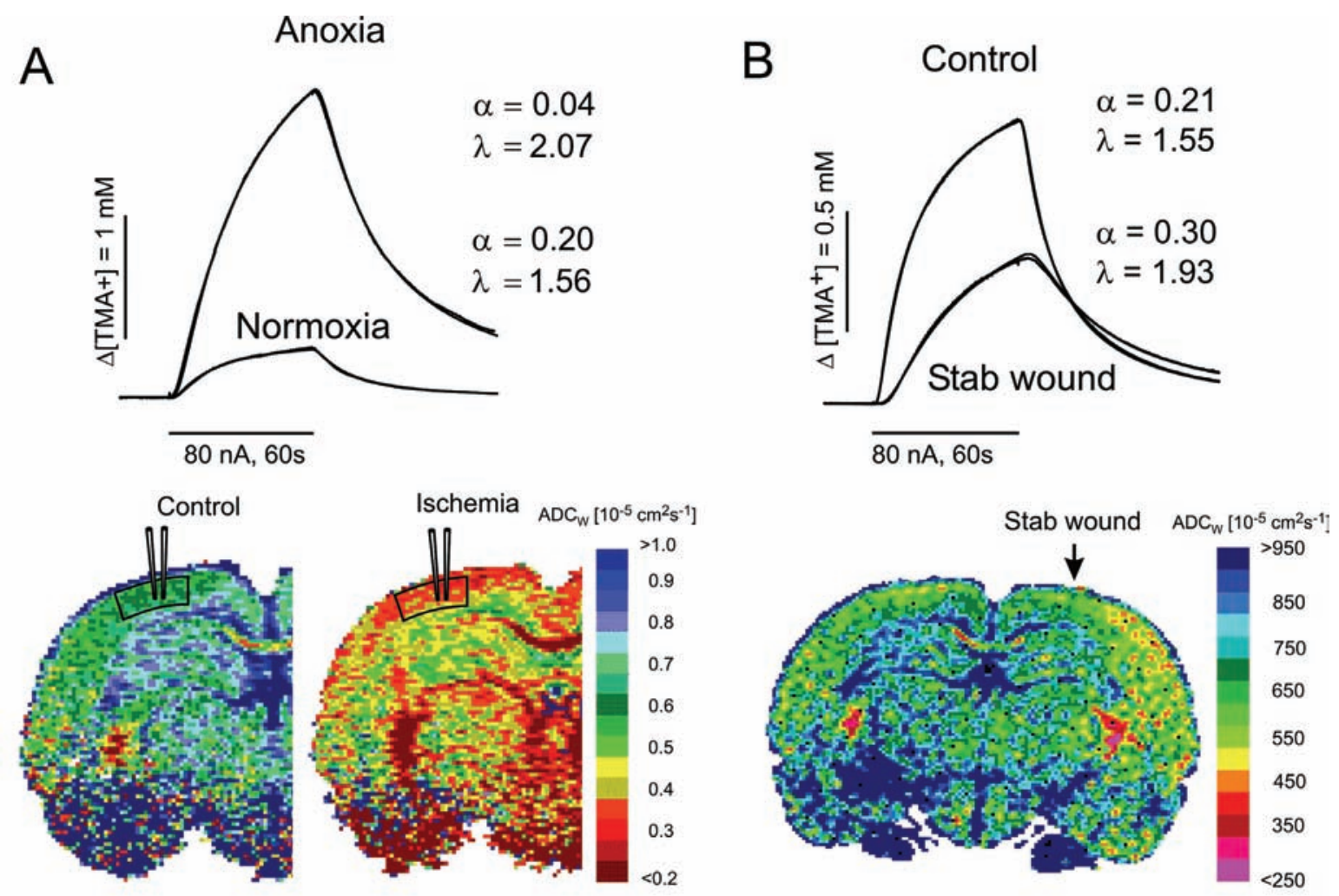

Fig. 3. Typical $\mathrm{TMA}^{+}$diffusion curves measured with the real-time iontophoretic method and maps of the apparent diffusion of water $\left(A D C_{W}\right)$ measured by diffusion-weighted MRI in the rat cortex during acute and chronic pathological states represented by anoxia (A) and traumatic injury (B), respectively. During anoxia, a dramatic shrinkage of the ECS volume fraction $\alpha$ due to cell swelling is accompanied by a marked increase in tortuosity $\lambda$. In the tissue 7 days after a stab wound injury, $\alpha$ and $\lambda$ behave independently and are both increased. Maps of the $A D C_{w}$ (bottom part of the figure) show that the diffusion of water is slowed down in both pathological states.

the ECS volume fraction initially increased and then returned to control values, apparently due to cell loss in the area followed by the replacement of damaged tissue by a gliotic scar (Roitbak and Syková 1999). Tortuosity values reached a maximum at 7 days post-wounding (Fig. 3B). In the ipsilateral cortex at a greater distance from the wound (1500-2000 $\mu \mathrm{m})$, an increase of tortuosity was found, accompanied by no increase in GFAP staining but with an increase in chondroitinsulphate proteoglycan (CSPG) expression. Diffusion measurements using DW-MRI showed an increase in $\mathrm{ADC}_{\mathrm{w}}$ in the close vicinity of the wound, i.e. in the region of cell death, while otherwise $\mathrm{ADC}_{\mathrm{w}}$ decreased throughout the whole ipsilateral hemisphere, related to the additional diffusion barriers caused by deposits of ECM molecules (Voříšek et al. 2002). The formation of gliotic tissue and ECM production not only in the wounded area, but also in a rather large area of adjacent tissue, is thus responsible for a long-lasting increase of diffusion barriers in the ECS, preventing or slowing down the diffusion of neuroactive substances and growth factors and leading to impaired extrasynaptic transmission, cell-to-cell communication and regenerative processes and possibly to functional deficits even in areas remote from the injury site.

Independent changes of ECS volume and tortuosity were also found in two pathologies connected with tissue remodeling - in dysplastic cortical tissue and in brain tumors. The studies were performed in human tissue slices obtained from surgically treated patients. In humans, malformations of cortical development, including focal cortical dysplasias, represent a prominent cause of medically intractable epilepsy. Most hypotheses concerning the mechanisms of seizure activity in the dysplastic cortex are based on alterations in synaptic transmission and glial dysfunction (Najm et al. 2004). Recent measurements in human epileptic tissue slices, however, showed that the diffusion properties of dysplastic areas are altered and may represent another factor contributing to epileptogenicity (Vargová et al. 2006). Diffusion in dysplastic cortical areas is compromised by increased diffusion barriers, leading to a rise in tortuosity, arising from several causes: loss of cortical stratification, deposits of extracellular matrix 
molecules such as tenascin and an increased number of astrocytic processes (Vargová et al. 2006). Impaired diffusion thus may contribute to the greater local accumulation of neuroactive substances and facilitate the development of epileptic seizures.

Our studies of human glioma samples showed that the migratory abilities of tumor cells and the malignant potential of the tumors might be strongly affected by changes in ECS volume fraction and ECM molecule content (Vargová et al. 2003, Zámečník et al. 2004). As a control, cortical tissue that did not exhibit any histological signs of pathological changes, resected during the surgical treatment of intractable epilepsy, was used.

The measurements in human brain tumors showed that the malignancy grade of astrocytomas and their proliferative activity assessed by the labeling indices MIB-1 and anti-topo-II $\alpha$, are directly proportional to increasing values of $\alpha$ and $\lambda$ (Vargová et al. 2003). The increase in $\alpha$ and $\lambda$ in high-grade tumors strongly correlated with an increased accumulation of ECM molecules, particularly of tenascin and vitronectin (Zámečník et al. 2004), which have been shown to correspond with tumor malignancy (Zhang et al. 1998). This can serve to improve the preoperative prediction of tumor malignancy and therefore affect the extent of surgery.

\section{Role of the extracellular matrix (ECM)}

The ECM is one of the factors that create diffusion barriers and affect tortuosity (see above). Generally, the structural net of the ECM constitutes three different types of macromolecules: gylycosaminoglycans represented by hyaluronic acid, chondroitinsulphate proteoglycans (CSPG), especially their lectican family and oligomeric glycoproteins tenascins. Hyaluronan is highly hydrated, so it is suspected to play a role in regulating the width of the ECS, especially in the developing brain where an abundance of massively hydrated hyaluronan has been reported (Bignami and Asher 1992). A role in the regulation of extracellular space volume has also been demonstrated for tenascins, which are expressed during various pathological states, e.g. tumors (Zámečník et al. 2004).

ECM content changes dynamically during development, aging, wound healing and various pathological states. The functions of ECM molecules are numerous: together with fine astrocytic processes, they form perineuronal nets around synapses (Celio et al. 1998) and they are also involved in cell migration, proliferation and differentiation during the development of the CNS (Sobeih and Corfas 2002), oriented axonal growth, synapse and memory formation (Wright et al. 2002, Dityatev and Schachner 2003) and in remodeling the adult CNS after injury, where ECM molecules create additional diffusion barriers and contribute, together with astrogliosis, to an increase in tortuosity.

ECM molecules also play a role in tissue cytoarchitecture by maintaining the optimal size of intercellular pores. A significant decrease in ECS volume was found in genetically modified, tenascin-R negative mice (Syková et al. 2005). On the other hand, an increase in $\alpha$ has been found in pathological states with an overproduction of ECM: during astrogliosis (Roitbak and Syková 1999) or in the tissue of primary brain tumors (Zámečník et al. 2004). The role of the ECM in determining the ECS volume can also be demonstrated by the changes seen during aging, where a decrease in the amount of CSPG and fibronectin seen in the hippocampus of old rats with severe learning disability coincided with a decrease in the ECS volume (Syková et al. 2002). Our study also revealed that the degree of learning impairment during aging closely correlates with a loss of anisotropy in the hippocampal CA1 region and the dentate gyrus due to a loss of the typical organization of glial processes. In comparison with rats that showed a prominent learning deficit in a Morris water maze task, a significant decrease in $\alpha$ and a complete loss of anisotropy in the hippocampus, aged rats with a milder learning impairment showed a smaller $\alpha$ decrease and a substantial degree of anisotropy still present. DW-MRI measurements confirmed impaired diffusion in the hippocampus as well as in the cortex of aged animals. It is therefore reasonable to assume that diffusion anisotropy, which leads to a certain degree of specificity in extrasynaptic communication by channeling the flux of substances in a preferential direction, may play an important role in memory formation (Syková et al. 2002).

\section{Conclusions}

The movement of neuroactive substances through the extracellular space of the CNS is the basic mechanism of extrasynaptic or volume transmission. In acute physiological as well as pathological states, diffusion in the ECS is affected by cell (especially glial) swelling, resulting from ionic and water shifts between 
intra- and extracellular compartments. In more slowly developing or chronic states, diffusion is affected mostly by structural changes of the tissue related to myelination and the rebuilding of fine astrocytic processes during development, lactation, aging, injury and degenerative diseases, accompanied by astrogliosis and the production of extracellular matrix. Changes in the diffusion parameters influence both synaptic and extrasynaptic transmission; they may enhance or, conversely, suppress neuronal activity, and the accumulation of neuroactive substances (e.g., glutamate) due to a decrease in ECS volume and the loss of diffusion anisotropy may contribute to functional deficits. The diffusion properties of the tissue may play a role in the pathogenesis of brain tumors or intractable epilepsy, are important for considering therapeutic drug application and, last but not least, they may be a valuable source of information for diagnostic purposes.

\section{Conflict of Interest}

There is no conflict of interest.

\section{Acknowledgements}

Supported by grants 1M0538 and LC554 from the Ministry of Education, Youth and Sports of the Czech Republic.

\section{References}

ARAQUE A, PARPURA V, SANZGIRI RP, HAYDON PG: Tripartite synapses: glia, the unacknowledged partner. Trends Neurosci 22: 208-215, 1999.

ASZTELY F, ERDEMLI G, KULLMANN DM: Extrasynaptic glutamate spillover in the hippocampus: dependence on temperature and the role of active glutamate uptake. Neuron 18: 281-293, 1997.

BIGNAMI A, ASHER R: Some observations on the localization of hyaluronic acid in adult, newborn and embryonal rat brain. Int J Dev Neurosci 10: 45-57, 1992.

CELIO MR, SPREAFICO R, DE BIASI S, VITELLARO-ZUCCARELLO L: Perineuronal nets: past and present. Trends Neurosci 21: 510-515, 1998.

DITYATEV A, SCHACHNER M: Extracellular matrix molecules and synaptic plasticity. Nat Rev Neurosci 4: 456-468, 2003.

FUXE K, AGNATI LF: Volume Transmission in the Brain: Novel Mechanisms for Neural Transmission. Raven Press, New York, 1991.

HAYDON PG: GLIA: listening and talking to the synapse. Nat Rev Neurosci 2: 185-193, 2001.

HERKENHAM M: Mismatches between neurotransmitter and receptor localizations in brain: observations and implications. Neuroscience 23: 1-38, 1987.

HOMOLA A, ZOREMBA N, ŠLAIS K, KUHLEN R, SYKOVÁ E: Changes in diffusion parameters, energy-related metabolites and glutamate in the rat cortex after transient hypoxia/ischemia. Neurosci Lett 404: 137-142, 2006.

CHVÁTAL A, ANDĚROVÁ M, HOCK M, PRAJEROVÁ I, NEPRAŠOVÁ H, CHVÁTAL V, KIRCHHOFF F, SYKOVÁ E: Three-dimensional confocal morphometry reveals structural changes in astrocyte morphology in situ. J Neurosci Res 85: 260-271, 2007.

CHVÁTAL A, ANDĚROVÁ M, SYKOVÁ E: Analysis of $\mathrm{K}^{+}$accumulation reveals privileged extracellular region in the vicinity of glial cells in situ. $J$ Neurosci Res 78: 668-682, 2004.

KILB W, DIERKES PW, SYKOVÁ E, VARGOVÁ L, LUHMANN HJ: Hypoosmolar conditions reduce extracellular volume fraction and enhance epileptiform activity in the CA3 region of the immature rat hippocampus. J Neurosci Res 84: 119-129, 2006.

KISS JP, ZSILLA G, VIZI ES: Inhibitory effect of nitric oxide on dopamine transporters: interneuronal communication without receptors. Neurochem Int 45: 485-489, 2004.

KUFFLER SW, POTTER DD: Glia in the leech central nervous system: physiological properties and neuron-glia relationship. J Neurophysiol 27: 290-320, 1964.

KULLMANN DM, ERDEMLI G, ASZTELY F: LTP of AMPA and NMDA receptor-mediated signals: evidence for presynaptic expression and extrasynaptic glutamate spill-over. Neuron 17: 461-474, 1996. 
LEHMENKUHLER A, SYKOVÁ E, SVOBODA J, ZILLES K, NICHOLSON C: Extracellular space parameters in the rat neocortex and subcortical white matter during postnatal development determined by diffusion analysis. Neuroscience 55: 339-351, 1993.

MAZEL T, ŠIMONOVÁ Z, SYKOVÁ E: Diffusion heterogeneity and anisotropy in rat hippocampus. Neuroreport 9: 1299-1304, 1998.

NAJM I, YING Z, BABB T, CRINO PB, MACDONALD R, MATHERN GW, SPREAFICO R: Mechanisms of epileptogenicity in cortical dysplasias. Neurology 62 (Suppl 3): S9-S13, 2004.

NEPRAŠOVÁ H, ANDĚROVÁ M, PETŘíK D, VARGOVÁ L, KUBÍNOVÁ S, CHVÁTAL A, SYKOVÁ E: High extracellular $\mathrm{K}^{+}$evokes changes in voltage-dependent $\mathrm{K}^{+}$and $\mathrm{Na}^{+}$currents and volume regulation in astrocytes. Pflugers Arch 453: 839-849, 2007.

NICHOLSON C, PHILLIPS JM: Ion diffusion modified by tortuosity and volume fraction in the extracellular microenvironment of the rat cerebellum. $J$ Physiol Lond 321: 225-257, 1981.

NICHOLSON C, SYKOVÁ E: Extracellular space structure revealed by diffusion analysis. Trends Neurosci 21: 207215, 1998.

NORTON WT, AQUINO DA, HOZUMI I, CHIU FC, BROSNAN CF: Quantitative aspects of reactive gliosis: a review. Neurochem Res 17: 877-885, 1992.

OLIET SH, PIET R, POULAIN DA: Control of glutamate clearance and synaptic efficacy by glial coverage of neurons. Science 292: 923-926, 2001.

PIET R, VARGOVÁ L, SYKOVÁ E, POULAIN DA, OLIET SH: Physiological contribution of the astrocytic environment of neurons to intersynaptic crosstalk. Proc Natl Acad Sci USA 101: 2151-2155, 2004.

PROKOPOVÁ S, VARGOVÁ L, SYKOVÁ E: Heterogeneous and anisotropic diffusion in the developing rat spinal cord. Neuroreport 8: 3527-3532, 1997.

RICE ME, OKADA YC, NICHOLSON C: Anisotropic and heterogeneous diffusion in the turtle cerebellum: Implications for volume transmission. J Neurophysiol 70: 2035-2044, 1993.

ROITBAK T, SYKOVÁ E: Diffusion barriers evoked in the rat cortex by reactive astrogliosis. Glia 28: 40-48, 1999.

ŠLAIS K, VOŘISSSEK I, ZOREMBA N, HOMOLA A, DMYTRENKO L, SYKOVÁ E: Brain metabolism and diffusion in the rat cerebral cortex during pilocarpine-induced status epilepticus. Exp Neurol 209: 145-154, 2008.

SOBEIH MM, CORFAS G: Extracellular factors that regulate neuronal migration in the central nervous system. Int $J$ Dev Neurosci 20: 349-357, 2002.

SVOBODA J, SYKOVÁ E: Extracellular space volume changes in the rat spinal cord produced by nerve stimulation and peripheral injury. Brain Res 560: 216-224, 1991.

SYKOVÁ E: Diffusion parameters of the extracellular space. Israel J Chem 43: 55-69, 2003.

SYKOVÁ E: Diffusion properties of the brain in health and disease. Neurochem Int 45: 453-466, 2004a.

SYKOVÁ E: Extracellular space in the CNS: its regulation, volume and geometry in normal and pathological neuronal function. Neuroscientist 3: 28-41, 1997.

SYKOVÁ E: Extrasynaptic volume transmission and diffusion parameters of the extracellular space. Neuroscience 129: $861-876,2004 b$.

SYKOVÁ E: Glia and volume transmission during physiological and pathological states. J Neural Transm 112: 137$147,2005$.

SYKOVÁ E, MAZEL T, HASENOHRL RU, HARVEY AR, ŠIMONOVÁ Z, MULDERS WH, HUSTON JP: Learning deficits in aged rats related to decrease in extracellular volume and loss of diffusion anisotropy in hippocampus. Hippocampus 12: 269-279, 2002.

SYKOVÁ E, MAZEL T, ŠIMONOVÁ Z: Diffusion constraints and neuron-glia interaction during aging. Exp Gerontol 33: 837-851, 1998.

SYKOVÁ E, VARGOVÁ L, PROKOPOVÁ S, ŠIMONOVÁ Z: Glial swelling and astrogliosis produce diffusion barriers in the rat spinal cord. Glia 25: 56-70, 1999.

SYKOVÁ E, VOŘÍŠEK I, MAZEL T, ANTONOVA T, SCHACHNER M: Reduced extracellular space in the brain of tenascin-R- and HNK-1-sulphotransferase deficient mice. Eur J Neurosci 22: 1873-1880, 2005.

THEODOSIS DT, POULAIN DA: Activity-dependent neuronal-glial and synaptic plasticity in the adult mammalian hypothalamus. Neuroscience 57: 501-535, 1993. 
VAN DER TOORN A, SYKOVÁ E, DIJKHUIZEN RM, VOŘÍŠEK I, VARGOVÁ L, ŠKOBISOVÁ E, VAN LOOKEREN CAMPAGNE M, REESE T, NICOLAY K: Dynamic changes in water ADC, energy metabolism, extracellular space volume, and tortuosity in neonatal rat brain during global ischemia. Magn Reson Med 36: 52-60, 1996.

VAN HARREVELD A, DAFNY N, KHATTAB FI: Effects of calcium on electrical resistance and the extracellular space of cerebral cortex. Exp Neurol 31: 358-367, 1971.

VARGOVÁ L, HOMOLA A, ZÁMEČNÍK J, MARUSIC P, KRŠEK P, SYKOVÁ E: Extracellular space diffusion parameters of cortical dysplasias in human epileptic tissue. Sfn 36th Annual Meeting CD viewer and planner, 2006.

VARGOVÁ L, HOMOLA A, ZÁMEČNÍK J, TICHÝ M, BENEŠ V, SYKOVÁ E: Diffusion parameters of the extracellular space in human gliomas. Glia 42: 77-88, 2003.

VARGOVÁ L, CHVÁTAL A, ANDĚROVÁ M, KUBÍNOVÁ S, ŽIAK D, SYKOVÁ E: Effect of osmotic stress on potassium accumulation around glial cells and extracellular space volume in rat spinal cord slices. $J$ Neurosci Res 65: 129-138, 2001a.

VARGOVÁ L, JENDELOVÁ P, CHVÁTAL A, SYKOVÁ E: Glutamate, NMDA, and AMPA induced changes in extracellular space volume and tortuosity in the rat spinal cord. J Cereb Blood Flow Metab 21: 1077-1089, $2001 b$.

VIZI ES: Interaction between adrenergic and cholinergic systems: presynaptic inhibitory effect of noradrenaline on acetylcholine release. J Neural Transm Suppl 11: 61-78, 1974.

VIZI ES, KISS JP, LENDVAI B: Nonsynaptic communication in the central nervous system. Neurochem Int 45: 443451, 2004.

VORÍŠEK I, HÁJEK M, TINTĚRA J, NICOLAY K, SYKOVÁ E: Water ADC, extracellular space volume, and tortuosity in the rat cortex after traumatic injury. Magn Reson Med 48: 994-1003, 2002.

VORÍŠEK I, SYKOVÁ E: Evolution of anisotropic diffusion in the developing rat corpus callosum. $J$ Neurophysiol 78: 912-919, 1997a.

VORÍŠEK I, SYKOVÁ E: Ischemia-induced changes in the extracellular space diffusion parameters, $\mathrm{K}^{+}$, and $\mathrm{pH}$ in the developing rat cortex and corpus callosum. J Cereb Blood Flow Metab 17: 191-203, $1997 \mathrm{~b}$.

WRIGHT JW, KRAMAR EA, MEIGHAN SE, HARDING JW: Extracellular matrix molecules, long-term potentiation, memory consolidation and the brain angiotensin system. Peptides 23: 221-246, 2002.

ZÁMEČNÍK J, VARGOVÁ L, HOMOLA A, KODET R, SYKOVÁ E: Extracellular matrix glycoproteins and diffusion barriers in human astrocytic tumours. Neuropathol Appl Neurobiol 30: 338-350, 2004.

ZHANG H, KELLY G, ZERILLO C, JAWORSKI DM, HOCKFIELD S: Expression of a cleaved brain-specific extracellular matrix protein mediates glioma cell invasion In vivo. $J$ Neurosci 18: 2370-2376, 1998.

ZOLI M, JANSSON A, SYKOVÁ E, AGNATI LF, FUXE K: Intercellular communication in the central nervous system. The emergence of the volume transmission concept and its relevance for neuropsychopharmacology. Trends Pharmacol Sci 20: 142-150, 1999. 